\title{
La fantasía porteña: escritoras peruanas en la Buenos Aires de entresiglos
}

\section{The porteño fantasy: Peruvian women writers in the Buenos Aires of fin de siècle}

María Vicens ${ }^{1}$

\section{Resumen}

Entre 1890 y 1910, varias escritoras peruanas vieron en Buenos Aires una posibilidad de reinventar sus carreras literarias, impulsadas por el temprano interés que la prensa porteña había mostrado por sus textos. Este alentador panorama, sin embargo, contrastaría muy pronto con la realidad:las experiencias que Clorinda Matto de Turner, Mercedes Cabello de Carbonera y Carolina Freyre de Jaimes protagonizaron en la capital argentina exponenespecialmente los obstáculos que encontraron en una ciudad en pleno proceso de modernización, así como las estrategias que desplegaron para readaptar sus perfiles autorales con el fin depoder participar en el campo cultural local.

1 Profesora y licenciada en Letras por la Universidad de Buenos Aires y magíster en Estudios Interdisciplinares de Género por la Universidad de Salamanca. Contacto: mavicens@gmail.com 
Palabras clave: escritoras, siglo XIX, redes culturales, prensa, literatura latinoamericana

\begin{abstract}
Between 1890 and 1910 several Peruvian womenwriters saw in Buenos Aires a chance to reinvent their literary careers, driven by the early interest that the porteño press had shown for their texts. This encouraging panorama, however, would soon contrast with reality: the experiences that Clorinda Matto de Turner, Mercedes Cabello de Carbonera and Carolina Freyre de Jaimes starred in the Argentine capital expose especially the obstacles they encountered in a city in the midst of modernization, as well as the strategies they deployed to readapt their author profiles and participate therefore in the local cultural field.
\end{abstract}

Keywords: Women writers, 19th century, cultural networks, press, Latin American Literature

$$
* * *
$$

La guerra del Pacífico (1879-1883) no solo marcó un punto de giro para la sociedad peruana de finales del siglo XIX, sino también un reposicionamiento desus vínculos con países limítrofes que no habían participado directamente del conflicto, como la Argentina. Las simpatías entre ambas naciones, que se 78 remontaban a los tiempos de la Independencia y de la campaña emancipadorade José de San Martín, se consolidaronen este período, de modo que se nuclearon en la cosmopolita Buenos Aires, ciudadque estaba atravesando un significativo proceso de crecimiento y modernización vinculado conel fortalecimiento delestado y del modelo agroexportador. En este contexto, la capital argentina se erigió en un polo de atracción para los letrados peruanos, sobre todo para las mujeres, quienes ha- 
bían alcanzado un rol protagónico en la escena literaria limeña durante las décadas de 1870 y 1880 alentadas por la escritora argentina Juana Manuela Gorriti (1816-1892). De esta manera, diferentes proyectos periodísticos como El Álbum (1874-1975) y La Alborada (1875-1876), dirigidos por Gorriti, y El Perú Ilustrado (1887-1892), y ámbitos de sociabilidad como el Círculo Literario y las Veladas Literarias organizadas en la casa de la salteña conformaron, como ha señalado Francesca Denegri (1996), la primera generación de mujeres ilustradas de su país. Este grupo de letradas, que ganó reconocimiento y ocupó importantes espacios en la escena cultural limeña de 1880, se vioafectado por la guerra y los conflictos políticos internos del Perú,fenómenos que desencadenaron un proceso de diáspora que tuvo aBuenos Aires como sede principal.

Durante la última década del siglo XIX y la primera del XX, varias escritoras que habían ganado fama en la Lima de 1870 y 1880 recalaron en la capital argentina por diversos motivos: Clorinda Matto de Turner (1852-1909) y Aurora Cáceres (1877-1958) se exiliaron en esta ciudad en 1895, al ser derrocado el gobierno de Andrés Cáceres; Mercedes Cabello de Carbonera (1845-1909) residió allíun año en 1898 para participar del Congreso Pedagógico Internacional y tomar distancia de las críticas y conflictos que enfrentaba en Lima; Carolina Freyrede Jaimes (1844-1916), por su parte, se instaló con su marido, luego de varios años de residencia en Bolivia;Margarita Práxedes Muñoz (1848-1909) se estableció en la capital argentina a mediados de los 90, tras varios años de residencia en Chile;y Teresa González de Fanning viajó más tarde, en 1910, para participar del Congreso Femenino Internacional, junto a un numeroso grupo de pedagogas y activistas de su país. Este núcleo de escritoras peruanas en Buenos Aires se reorganizó en la capital argentina en torno a dos periódicos 
dedicados al público femenino: Búcaro Americano(1896-1901 y 1906-1908), fundado por Matto de Turner, y La Columna del Hogar (1899-1902),dirigido en su último año de publicación por Freyre de Jaimes. En las páginas de estas publicaciones, se actualizaron y readaptaron los debates políticos y literarios en torno de la mujer escritora que estas literatas ya habían protagonizado en Lima, así como el circuito de relaciones peruanoargentinas para promoverla figura de la escritora americana en el contexto argentino de entresiglos y un nuevo lugar para estas mujeres de letras más vinculado a la docencia y a la profesionalización que a los círculos sociales y a las tertulias.

En esa línea, este trabajo pretende articular un breve panorama sobre las diversas trayectorias que estas escritoras peruanas desarrollaron en Buenos Aires, sobre lasexpectativas que tenían respecto de su nuevo país y las realidades que encontraron, así como sobre las estrategias de adaptación que implementaron para seguir publicando a pesar de diversos obstáculos y contratiempos. En este escenario de cambios, se producirá un viraje notable en la mayoría de sus trayectorias literarias: todas ellas abandonan la ficción cuando se instalan en la ciudad. Sin embargo, esta decisión, lejos de relacionarse con un abandono de las letras, se sostiene en su intención de afianzarse como escritoras en el campo cultural porteño de entresiglos -algunas de ellas llegaron a desarrollar un perfil profesional-, sobre todo, a través

80 de la publicación de textos pedagógicos y manuales escolares, libros de misceláneas, y periódicos de diversa índole, como se analizará a lo largo de este artículo.

\section{Sueños y realidades}

El fin de siglo porteño está atravesado por claroscuros: tanto el proceso de modernización cultural y económica del país 
como el optimismo de la clase que se había instalado en el poder de la mano del roquismo en la década de 1880 mostraron sus fisuras frente a la crisis financiera de 1890, la primera de muchas en la historia argentina. Además de provocar la caída del gobierno de Miguel Ángel Juárez Celman, este episodio inauguraría una fase de autocrítica y replanteos dentro de un sector de la dirigencia liberal, y reforzaría una serie de tópicos y debates que ya se venían gestando en la década anterior (Zimmerman 1995). La crítica al lujo, la masiva inmigración europea, la especulación financiera, el trabajo femenino (centrado en la figura de la obrera), así como el derecho al voto universal se convirtieron en temas fundamentales de discusión: problemáticas en las que la mujer tenía un rol clave al funcionar como metáfora de la nación corrompida por el consumo, el comercio y el inmigrante advenedizo que escalaba rápidamente posiciones sociales, como ha analizado Francine Masiello (1997: 113-149). En este clima de fuerte circulación de discursos vinculados al positivismo ya la crítica moral, la mujer de letras ocuparía un espacio ambiguo, cruzado por la oportunidad y los límites.Por un lado, los discursos en boga la señalaban como la "redentora del hombre", como un faro moral para la nación y, en el marco de esta "misión", se expandieron sus posibilidades de intervenir en los debates públicos del período. Por otro lado, bajo este mismo rol social y moral, sin embargo, limitaron sus reclamos de mayores derechos - como eldivorcio y el voto-, y profundizarían las diferencias ideológicas entre las mujeres alineadas con el liberalismo burgués (ya fuesen socialistas o conservadoras) y las que defendían posturas de corte revolucionario y se identificaban, ante todo, con la clase obrera.

Esta división se observa claramente, por ejemplo, con un breve paneo a las revistas para el público femenino del período 
de entresiglos: mientras que publicaciones como Búcaro Americano, La Columna del Hogar, La Revista del Consejo Nacional de Mujeres y El Hogar buscaron interpelar a las mujeres de clases media y alta, a través del despliegue de un discurso centrado en la defensa de la maternidad, de la educación femenina y de ciertas profesiones para las mujeres como la docencia, así como en la crítica al consumo, a la "relajación moral" y a la "anarquía revolucionaria», las publicaciones socialistas o anarco-socialistas como La Voz de la Mujer (1896), Nosotras (1903-1904) y Unión y Labor (1909-1913) concentraron sus reclamos en abogar por mejores condiciones laborales para la mujer trabajadora, el derecho al voto y por el divorcio. Este último aspecto, sobre todo, operó como una verdadera bisagra entre ambos sectores, mientras que la maternidad, por el contrario, fue un tópico en cuya defensa todos estos periódicos coincidieron.

Más allá de los cuestionamientos y revisiones que la crisis provocó en la sociedad argentina en general, las escritoras peruanas que se instalaron en Buenos Aires a fines del siglo XIX vieron, en un principio, una oportunidad en ese agitado campo político-cultural y, en la Argentina, una posible patria por adopción. Así se encarga de subrayarlo Matto de Turner, por ejemplo, al rememorar su llegada a la capital porteña en Boreales, Miniaturas y Porcelanas:

Eran las ocho y media de la mañana del 15 de mayo de 1895 cuando Buenos Aires, la populosa, se presentaba amplia á nuestra vista. Convertido en realidad estaba, por fin, nuestro sueño acariciado desde la infancia de visitar la patria de nuestro abuelo, Juan José Usandivaras, la cuna de Juana Manuela Gorriti. [...] La ciudad se extiende sobre una superficie de 180 kilómetros cuadrados, mayor que la de París y Berlín. El censo de 1895 señalaba 663.854 habitantes, 
hoy pasan de 823.000. No es extraño este crecimiento si se atiende al enorme impulso que toma la inmigración debido á las leyes liberales, al carácter nacional, á la libertad de cultos y el ancho campo de trabajo que ofrece la República Argentina en su territorio tan vasto. (1902: 97-98).

Exiliada y prácticamente sin recursos para sobrevivir en su nueva ciudad, Matto de Turner ofrece una versión idealizada de Buenos Aires y trama una doble filiación que la une a los argentinos: la herencia sanguínea, por vía de su abuelo, y la herencia literaria, a través de su madre "del corazón” (183), la célebre Juana Manuela Gorriti, fallecida apenas algunos años antes y homenajeada en extensas reseñas y artículos en la prensa en ambos países. Esta última mención especialmente, lejos de ser casual, es sumamente significativa,ya que su mentora ocupó un rol clave tanto en la introducción de Matto de Turner-proveniente de Cusco- en el ambiente literario limeño como en la buena recepción que tuvieron las escritoras peruanas en la prensa argentina desde finales de la década de 1870. Figuras más o menos cercanas al círculo de Gorriti, como Cabello de Carbonera, González de Fanning, Freyre de Jaimes y la propia Matto de Turner, habían publicado numerosos textos en los semanarios porteños destinados al público femenino, gracias a las exitosas gestiones de la salteña, quien realizó varios viajes entre Lima y Buenos Airesentre finales de 1870 y principios de 1880 .

Estos intercambios establecieron un intenso diálogo entre las escritoras y la prensa de ambos países, y abrieron un prometedor camino para el fortalecimiento de la figura de la escritora americana. De hecho, la temprana circulación de las literatas peruanas en la prensa porteña de 1870 y 1880 redituó no solo en la posibilidad de desarrollar una carrera 
como publicistas durante el período de entresiglos (como en los casos de Matto y Freyre), sino en indicios previos que ya reflejaban el interés del campo literario porteño por sus obras, como la publicación simultánea en el Perú y en la Argentina de la primera novela de Matto de Turner, Aves sin nido, en 1889, y el premio que Cabello de Carbonera recibió de la Academia Literaria de Buenos Aires en 1892 por su ensayo La novela moderna. La buena relación entre esta última y el ambienteletrado argentino ya se había evidenciado en el prólogo de Blanca Sol (1889) -novela que sintoniza con el naturalismo en ascenso durante el período, a pesar de que su propia autora siempre mostró sus diferencias con la escuela de Emile Zola-. En el prólogo, Cabello de Carbonera toma como único referente americano a un escritor argentino, Eugenio Cambaceres, para defenderse de los ataques que recibía por la similitud entre su obra y la realidad limeña. Señala:

Hoy se le pide al novelista cuadros vivos y naturales, y el arte de novelar, ha venido a ser como la ciencia del anatómico [...] Y tan vivientes y humanas han resultado las creaciones de la fantasía, que más de una vez Zola y Daudet en Francia, Camilo Lemonnier en Bélgica y Cambaceres en la Argentina, hanse visto acusados, de haber trazado retratos cuyo parecido, el mundo entero reconocía, en tanto ellos no hicieron más que crear un tipo en el que imprimieron aquellos vicios o defectos que se proponían manifestar. (1889: II).

Al priorizar este referente en lugar de mencionar a colegas peruanos que también criticaban el romanticismo y defendían una literatura de denuncia política y social -nucleados en torno de la figura de Manuel González Prada-, Cabello de Carbonera recorta de su prólogo un aspecto que sería retomado por Matto de Turner en repetidas oportunidades durante su exilio porteño: para estas mujeres de letras, mientras 
el Perú había retrocedido políticamente después de la guerra del Pacífico, especialmente con el ascenso de Piérola, tanto los políticos como los letrados argentinos se abrían paso hacia unfuturo que incluía un ámbito de reconocimiento para las escritoras en lugar de la crítica, el escarnio, la excomunión e, incluso, la violencia. Frente a estos antecedentes, es casi esperable el optimismo con el que Matto de Turner escribió en un principio sobre la Argentina, tanto en sus ensayos laudatorios, como en su correspondencia privada. En la primera carta que dirigió a Ricardo Palma desde Buenos Aires, la escritora detalla:

Aquí, he sido acogida con mucho cariño. Me encuentro como entre los míos. Si yo pudiera trasladar á David, mis dos sobrinitos y la familia de usted que es todo lo que quiero, no pensaría en ausentarme. Todos nuestros amigos escritores y periodistas me han atendido a su recomendación particular. Ahora estoy escribiendo en El Tiempo que me paga 10 c por línea y en La Producción Nacional, que me da 10 pesos por columna. Con esto tengo para los extras. Querido Palma. Este es un gran país. Qué ciudad tan grande y tan bella. Todo es grandioso y el espíritu obrero desarrollado en alto grado. De día todo el mundo está en el taller, en la oficina, en el campo; de noche en el teatro. (9.IV.1895: 4-5).

Los detalles de Matto de Turner exudan optimismo y entusiasmo: lejos de la Lima que la había prácticamente expulsado por su intensa participación política y sus críticas al clero, la novelista aprovecha los contactos de un personaje conocido y querido en el ambiente porteño como Palma y apuesta fuerte en su llegada a la ciudad, gracias a su perfil de mujer viuda"profesionalizada por la necesidad", liberal en lo político, pero moderada en relación con las costumbres. Se convierte en una figura que genera interés y atracción, según 
detalla la propia escritora, al relatar que, además de conseguir trabajo como periodista, ha encontrado algunos parientes y conocido a "muchas amigas" de Buenos Aires y Montevideo, como la poeta Adela Castell.

Algunos meses después -y pese al"perverso" clima porteño que le provocaría un grave cuadro de influenza-, Matto de Turner sigue manteniendo su optimismo frente a su antiguo

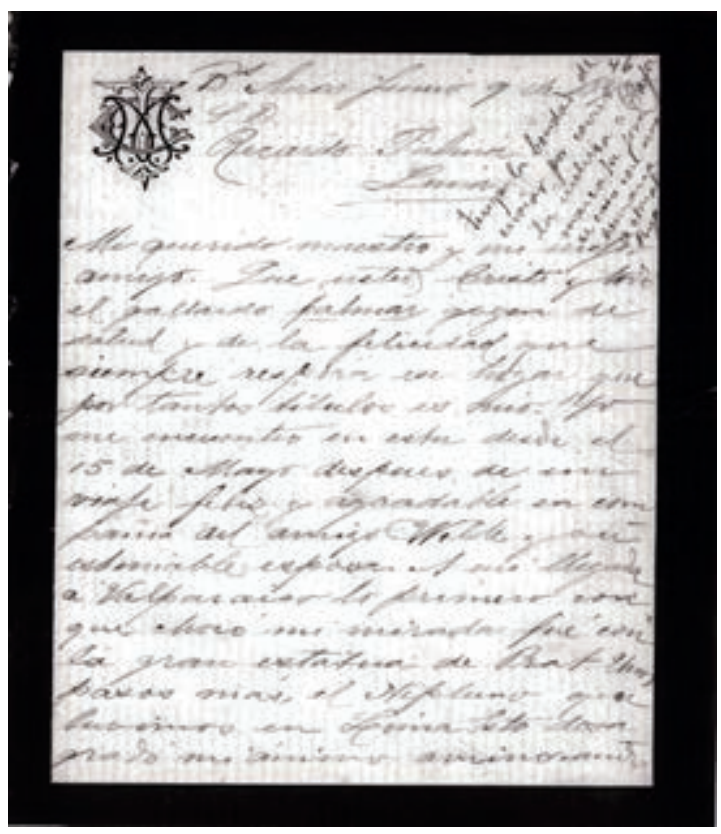

Carta de Clorinda Matto de Turner a Ricardo Palma. Buenos Aires, 9 de junio de 1896.

mentor y muestra los éxitos cosechados luego de tantos esfuerzos: en una carta del 1 de enero de 1896, le envía una copia de su célebre conferencia "Las obreras del pensamiento de la América del Sud", presentada en diciembre de 1895 
en el Ateneo de Buenos Aires, y le anuncia la fundación de su nueva revista, Búcaro Americano, financiada "bajo laprotección de varias sociedades de señoras" (1.I.1896: 3).Tanto el proyecto de la revista como su intervención en el Ateneo de Buenos Aires y las conexiones mencionadas en su correspondencia con Palma funcionan, en mi opinión, como estrategias de supervivencia de Matto de Turner en el exilio; son diferentes maneras de ocupar espacios en la escena literaria del momento: hacer circular sus textos, su nombre y, a través de estos hechos, visibilizar y legitimar su propia impronta autoral. Como Gorriti, Matto de Turner fue una hábil tejedora de redes culturales -sobre todo, a partir de los diversos proyectos periodísticos que encabezó en el Perú y la Argentina-. En ese proceso, desarrolló prácticas de legitimación femenina, a través del reconocimiento de otras mujeres como hermanas en las letras y de la exhibición de esos gestos públicamente para que sus colegas actuasen en forma recíproca con ella. Las portadas de Búcaro Americano, destinadas a retratar a personajes femeninos y masculinos de la sociedad argentina del momento, plasman de manera clara estas intenciones, ya que, en la mayoría de los casos, estas reseñas resaltan la amistad de Matto de Turner con los personajes homenajeados. No es menor detenerse en este punto, ya que, de acuerdo con los hechos, su modo de insertarse en la sociedad porteña de la época ofreció importantes resultados: además de ser una de las pocas escritoras que pudo sostener la publicación de una revista propia durante varios años, fue la primera mujer en dar una conferencia en el Ateneo de Buenos Aires y logró publicar varios libros desde que se instaló en la Argentina.

Frente a este panorama, las redes culturales y estrategias de legitimación que desarrolló Matto de Turner en el exilio parecen funcionar a la perfección. A primera vista, Buenos Aires 
se presenta en la realidad como esa fantasía de la que todos hablan: una tierra de progreso, de oportunidades. Ese sueño, sin embargo, duró poco. Para el mes de mayo de 1896, a pesar de haber resuelto sus dilemas económicos gracias a la obtención de un cargo en la Escuela Comercial de Mujeres, la mirada de Matto de Turner sobre la capital argentina comienza a resquebrajarse y las estrategias, a debilitarse.En una carta dirigida a Palma del 25 de mayo de 1896, señala, por ejemplo: "Cuando usted escriba á sus amigos de aquí, no deje de recomendarme. Creo que en ninguna parte del mundo se necesita de relaciones de amistad tanto como en esta" (25.V.1896: 3). Ese mundo porteño que la había recibido con brazos abiertos muestra, con el paso del tiempo, otras lógicas y, de pronto, sus contactos ya no parecen suficientes. Tampoco lo parecen ser sus vínculos con el grupo de peruanos residentes en Buenos Aires. En la misma carta, Matto se refiere a dos conferencias ofrecidas en el Ateneo por colegas peruanos y a su ausencia en ambos casos: "Con el resto de los peruanos yo no tengo injerencia alguna” (25.V.1896: 6), asegura. En cuanto a Búcaro Americano, una breverevisiónsobre su periódico alcanza para darse cuenta de que la empresa no ha resultado tan exitosa como las expectativas que había forjado en un principio su directora: "Si no me deja pérdidas confirmaré pero si ha de ser preciso perder tiempo, no seré tan cándida para no colgar Búcaro así con todas sus flores y sus viñetas" (25.V.1896:

88 5). Finalmente, en una nueva carta a Palma del 17 de julio de 1897, Matto niega cualquier rasgo positivo a su nueva vida y sentencia respecto a la vida cultural porteña: "Literariamente, aquí, el movimiento es nulo. Todos se preocupan del comercio y los negocios" (17.VII.1897: 5-6).

En contraposición a su optimismo inicial, Matto de Turner se desahoga en la intimidad y desdobla su discurso: si en 
librospublicados durante sus años en Buenos Aires, como Boreales, miniaturas y porcelanas (1902) o Cuatro conferencias sobre la América del Sur (1909), sigue cantando loas al progreso argentino, en su correspondencia privada muestra hasta qué punto su experiencia en el extranjero está atravesada de conflictos, nostalgia, desilusiones y soledad.

Un fenómeno similar, pero más extremo aun, se produce en el caso de Mercedes Cabello de Carbonera durante su breve residencia en la capital argentina. Ismael Pinto Vargas, quien ha reconstruido en detalle la vida de la novelista (2003: 745-787), señala como un punto de quiebre en el proceso de su declive autoral el escándalo que produce un discurso ofrecido en el Liceo Fanning en 1897, en el que la escritora arremete contra la educación religiosa para las mujeres. Flanqueada desde diversos sectores y enferma, la novelista decide viajar a Buenos Aires para consultar médicos y tomar distancia de la polémica, y envía desde allí una serie de crónicas a la prensa de su país. En oposición a las críticas y al escarnio de Lima, Cabello de Carbonera proyecta en estos escritos una Buenos Aires de oportunidades, tolerancia y progreso, llena de diarios y revistas en los que las mujeres pueden trabajar, y en permanente diálogo con Europa, que la recibe con los brazos abiertos. Este es el paisaje que describe en la primera correspondencia que envía a su amigo, el intelectual positivista Christian Dam, de su viaje a la Argentina y que se publica en el periódico El Libre Pensamiento:

Si viera usted qué hermosa y levantada es aquí la prensa, se arrodillaría usted en presencia de esos redactores que son como semi-dioses. [...] La Nación, La Prensa, La República, todos cumplieron con la cortesía de saludarme y de ofrecerme sus columnas; pero yo no he cumplido con enviarles ningún trabajo todavía, porque comprendo que si es cierto, 
que pagan a peso de oro esos trabajos, también es cierto que sólo aceptan cosas de gran importancia y utilidad; [...] en este país hay recursos para todos; en el hospital nacional hay un consultorio, tres veces por semana, de esos médicos que cobran cincuenta soles por visita y la consulta es gratis [...] esos monumentales hospitales son más bien palacios, con parques lindísimos, con corredores ventilados y en alto [...]. (Pinto Vargas 2003: 773).

En la mirada de Cabello de Carbonera, la capital argentina asoma como la ciudad capaz de darle lo que Lima le niega en ese momento: reconocimiento simbólico y material por parte de la prensa -que paga "a peso de oro" el trabajo intelectualy un sistema público de salud al día con cualquier hospital de Europa. Sabemos,como ha analizado extensamente la crítica argentina (Altamirano y Sarlo 1983; Dalmaroni, 2006; Laera, 2014), que esta imagen idealizada contrasta no solo con la realidad del periodismo de la época, sino también con los discursos que circulan en torno de la prensa y de la profesionalizaciónen ese momento, los cuales se enfocaban más en las dificultades y obstáculos que este proceso exponeque en sus posibilidades económicas (Roberto Payró emerge en este punto como el ejemplo más claro).Sin embargo, la fantasía porteña se repite una vez más, como en el caso de Matto y la crónica sobre su llegada a la ciudad incluida en Boreales, Miniaturas y Porcelanas, y a diferencia del clima de ideas a nivel local. Y también, como en el caso de su colega serrana, estas expectativas se verán rápidamente frustradas a medida que avanzasu estanciaen la ciudad y el desahogo será destinado al ámbito de la correspondencia privada.

Lejos de encontrarse con una buena recepción y con pares interesadas en relacionarse con ella -lo esperable por ser una figura conocida en el ámbito argentino-, la novelista detalla 
sus males a Palma, y subraya su sensación de desamparo y soledad. En una carta del 12 de junio de 1898,relata: "La vida aquí es para mí un continuado suplicio. Enfermedades, falta completa de distracciones por no tener un acompañante ni hombre ni mujer para irme á teatros o paseos elegantes. [...] para mí todo es triste y pálido" (12.VI.1898: 5).La novelista exitosa, la ensayista premiada por la Academia Literaria de Buenos Aires, la escritora peruana conocida en el ambiente

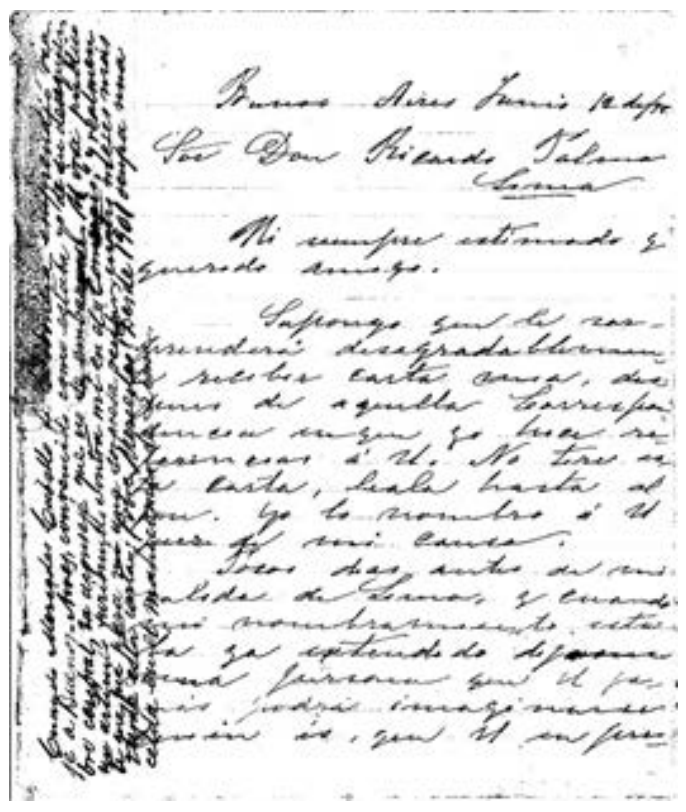

Carta de Mercedes Cabello de Carbonera a Ricardo Palma.

Buenos Aires,12 de junio de 1898.

porteño debido a sus numerosas colaboraciones en la prensa de esta ciudad, se diluye frente a esta sensación de aislamiento y soledad. La realidad se impone sobre las fantasías; las redes de sociabilidad no parecen funcionar lejos del hogar, lejos de la época de oro del Club Literario, lejos de la figura 
de Juana Manuela Gorriti. Cabello de Carbonera ni siquiera logra reencontrarse con Matto de Turner, quien hacía años residía en la ciudad, según le explica a Palma: "A Clorinda no la he visto más que una vez. Sigue de profesora en un colegio. No he podido visitarle porque en la mudanza de B.A. A este pueblo [Belgrano], perdí su tarjeta y no conozco su dirección" (15.IX.1898: 3). Perdida y desorientada, la falta de contacto ya no se trata de un problema de competencia entre ambas novelistas, como en los gloriosos años 80 , cuando ambas ocupaban espacios centrales en el campo literario limeño, ${ }^{2}$ sino más bien de los problemas que debe enfrentar una mujer en una capital extranjera: asegura que no puede encontrarse con su amiga aunque quiera; está perdida en la ciudad, no conoce sus calles, su clima la enferma, nadie la visita. Su situación es planteada por ella misma de manera tan extrema y dramática que Palma interpreta su discurso como un signo irrefutable del avance de su enfermedad.En una nota al margen, escribe de puño y letra:

Cuando Mercedes Cabello de Carbonera emprendió viaje a Buenos Aires convencida como estaba de su desequilibrio cerebral, la desaconsejé que no se embarcase. $\mathrm{Al}$ irse publicó una artículo furibundo contra mí en "El Comercio", y realmente que fue para mí una sorpresa recibir una carta meses más tarde. ¡Pobre Mercedes! Desde 1901 ocupa una celda en el manicomio de Lima. (12.VI.1898: 1).

2 En la correspondencia publicada de Gorriti a Palma se hacen varias referencias a los vaivenes en la amistadentre Matto de Turner y Cabello de Carbonera, "desavenencias" que, según da a entender Gorriti, están más relacionadas con los celos profesionales de dos escritoras en ascenso que a un conflicto de fondo. Véase la edición de Graciela Batticuore (2004) del epistolario. 
A pesar de que en esa misma carta la propia Mercedes le explica por qué se había enojado con él y había escrito un artículo en su contra, Palma ignora estos argumentos y reinterpreta $a$ posteriori su escritura en relación con la enfermedad de Cabello. A través de esta intervención en su propia correspondencia, el escritor direcciona la lectura y las interpretaciones que se deben realizar de estos intercambios y de su amistad con la novelista. Más allá de que, efectivamente, algunos años más tardeCabello de Carbonera fuera internada en el manicomio de Lima, y de que sus continuas referencias a males cerebrales indicaran que se sentía enferma, el cruce de estas cartas con las que escribió Matto de Turner indica un fenómeno que, en mi opinión, va más allá de la situación particular de la novelista y se vincula con los límites que plantean las redes de sociabilidad transnacionales y la lógica de la "sororidad republicana" (Cott, 1977; Peluffo, 2005a, 2015; Fernández, 2015) para estas autoras. A diferencia de los sueños que habían proyectado en la Lima de posguerra, la realidad en la cosmopolita Buenos Aires muestra su cara más cruda: nadie las va a contactar ni se va a preocupar por ellas si ellas mismas no se preocupan por relacionarse con los círculos sociales de la ciudad. Las peruanas se sienten marginadas y, sin contactos; no parecen encontrarlos contactos ni circuitos proyectados a distancia una vez instaladas en esa coyuntura extrajera. Y, frente a esta experiencia de aislamiento, se desahogan en la intimidad, expresando su decepción frente a la falta de posibilidad para generar nuevos espacios de intercambio o de tener un rol protagónico en el ámbito porteño.

\section{Adaptarse para sobrevivir}

Las dificultades y desencuentros que emergen de la correspondencia de Cabello de Carbonera y Matto de Turner obli- 
gan a replantearse el modo en que se han analizado las redes que estas escritoras peruanas de fines del siglo XIX trazaron entre sí ycon colegas de otros países, ya que el panorama que estas cartas plantean complejiza una experiencia que en la prensa de la época y en sus propios libros se representa en términos mucho más optimistas y estimulantes de lo que ellas mismas confesaron, por momentos, en privado. Así, se instala una clara dualidad entre la mirada íntima y confidente, y la imagen que se proyecta hacia el exterior, a través de sus conferencias, artículos y ensayos. ${ }^{3} \mathrm{Si}$ bien es claro que esta políticas de amistad no funcionan en forma tan aceitada como se esperaría en los casos mencionados, también es cierto que las obras de autoras conocidas como Matto de Turner y Cabello de Carbonera circularon en la sociedad porteña de entresiglos; son escritoras que, efectivamente, dejaron una huella -especialmente gracias a su labor periodística- y dejaron una huella importante como referentes en el campo de las letras femeninas americanas. En este sentido, la complejidad del panorama recuerda a la caracterización que Álvaro Fernández Bravo y Claudio Maíz (2009) hacen del concepto de red, como una categoría de "naturaleza dinámica e inestable que conecta puntos distantes entre sí y articula un territorio cultural de fronteras menos estables y tangibles que la nación" (2009: 13). Por este motivo, la red

3 Esta dualidad es especialmente clara en el caso de Matto de Turner, quien, mientras escribe a Palma sobre su situación de aislamiento y enojo con los residentes peruanos en Buenos Aires, sigue publicando Búcaro Americano, periódico en el que exhibe de manera sistemática sus contactos y amistades. La escritora sabe darse a conocer y visibilizar su figura mejor que ninguna otra escritora peruana del período. Para lograrlo, esconde su nostalgia y sentimiento de soledad, y se muestra como una literata importante y exitosa en su nuevo país. 
es elástica, porosa, transnacional, policéntrica, posubjetiva, coral " $y$ por lo tanto apropiada para dar cuenta de literaturas como las latinoamericanas, en formación y atravesadas por la errancia y el exilio" (2009: 13). Creo que esta forma de pensar la literatura de dicho período resulta muy eficaz para analizar los vínculos y proyectos que despliegan las escritoras peruanas en la Buenos Aires de entresiglos, sus vaivenes y estrategias de adaptación, así como de qué manera estas tácticas rearman el circuito literario y periodísticofemenino que había comenzado a constituirse en la Lima de finales de 1870, ahora en relación con otras lógicas del campo literario porteño y otras posibilidades de intervención en él.

Matto de Turner es la escritora que muestra de manera más clara estas estrategias de reacomodamiento. Gran parte del éxito profesional en su nueva vida porteña se vinculó con su capacidad de reinventar su impronta autoral a través de una estrategia central: la de dejar de lado la ficción -y evitar así cualquier tipo de debate relacionado con sus intervenciones en el ambiente limeño de posguerra en favor de una literatura comprometida y alineada con los planteos de Manuel González Prada, que tantos cuestionamientos y ataques habían provocado en torno a su figura- y volcar su escritura al periodismo profesional y a los libros de misceláneas, que compilan ensayos, semblanzas y conferencias, textos que exponen sistemáticamente sus contactos con hombres y mujeres destacados del continente americano. Como se haanalizado en la primera parte de este trabajo, estas expectativas en torno de la escritura profesional-es decir, las posibilidades iniciales que vislumbraba para vivir de su pluma- se vieron frustradas al poco tiempo de instalarse en la Argentina, tanto porque Matto de Turner no generó la tracción que había previsto con Búcaro Americano como por el hecho de que la 
comunidad de peruanos residentes en Buenos Aires estaba menos unida de lo que esperaba y el ambiente literario porteño no era tan receptivo a las escritoras como había pensado en un principio. En este contexto, la escritora mantuvo en pie su periódico (con extensos períodos de interrupción), principalmente, como una forma de conservar vigentes su impronta autoral y sus contactos, pero no logró alcanzar la trascendencia y el protagonismo que había tenido en el campo cultural limeño ni pudo mantenerse económicamente gracias a sus escritos, sino que vivió de la docencia.

Este último punto es central, ya que, a diferencia del caso peruano que, como ha estudiado Francesca Denegri (1996), alrededor de las décadas de 1860 y 1880 logró aglutinar a un grupo de escritoras que participaban activamente del campo literario limeño y que puede ser pensado en términos de "generación", en el contexto argentino de esos años no se llegó a conformar un fenómeno similar. Destacaron varias escritoras que fueron contemporáneas y se conocieron mutuamente_como Gorriti, Eduarda Mansilla, Josefina Pelliza de Sagasta, Lola Larrosa, Raymunda Torres y Quiroga, entre otras-;se produjeron publicaciones para el público femenino en las que circularon sus trabajos; hubo colegas hombres que promocionaron a la mujer de letras_como Rafael y Pastor Obligado en el caso de Gorriti o Ernesto Quesada más

96 hacia fin de siglo_- pero, a pesar de estas condiciones, no se llegó a formar un núcleo tan sólido como el de sus compatriotas en términos colectivos. Asimismo, para cuando las colegas y herederas de Gorriti en Lima recalaron en Buenos Aires hacia la década de 1890, la mayoría de estas iniciadoras ya había fallecido o retirado de la escena pública. En el campo cultural porteño de entresiglos, existía cierta expectativa respecto de las mujeres escritoras y de su incipiente profesio- 
nalización fomentada a nivel discursivo, especialmente desde la prensa, pero no se materializaba en la práctica. Es decir, no se concretaba lo que para Matto de Turner, Cabello de Carbonera, Freyre de Jaimes o la propia Gorriti implicaba ser una escritora: una figura capaz de publicar obras de ficción y poemas, generar proyectos periodísticos propios, e intervenir en el ambiente literario de su tiempo, ya fuese participando en asociaciones y tertulias o generando espacios de sociabilidad propios.

Considero que esta es la verdadera expectativa que se vio frustrada (o por lo menos entró en crisis) en la cosmopolita Buenos Aires de fin de siglo para sus residentes peruanas: la figura de la escritora entendida en términos decimonónicos, que reservaba para la ficción (y la novela más precisamente) el lugar más destacado de su obra y cuyo núcleo de influencia todavía estaba concentrado en ese hogar que funcionaba como un ámbito de sociabilidad intelectual y literaria. El desarrollo de redes culturales que se da como una estrategia de legitimación en la esfera pública y el circuito de publicaciones periódicas femeninas que funciona como escenario principal para visibilizar sus perfiles autorales no desaparecen, sino que se redimensionan; lo que cambia en ese clima porteño finisecular, en realidad, son los focos de interés, las posibilidades y los modelos de escritora. Uno de los personajes que mejor percibió esta serie de transformaciones fue Carolina Freyre de Jaimes, quien, a pesar de su avanzada edad, de las desventuras de su marido y de sus múltiples mudanzas, logró adaptarse una vez más a un contexto en el que era forastera. Esta vez fue en la sociedad porteña de entresiglos, donde llegó a dirigir un semanario de relativo éxito y obtuvo el cargo de secretaria en el célebre y aplaudido Consejo Nacional de Mujeres (Auza 1988: 125; Carlson 1988: 95). En un artículo 
titulado "Literatas y escritoras argentinas", publicado en La Columna del Hogar, Freyre de Jaimes sostiene:

La nuestra es época de evolución hacia ideales más prácticos, hacia los ideales del trabajo, de las profesiones y ocupaciones que aseguren, en cierto modo, la independencia de la mujer.

No es época literaria. La poesía sobre todo tiene en la Argentina pocas cultoras y pocas admiradoras. Ella fué, en otro tiempo, un extremecimiento luminoso en el alma de la humanidad y se halla hoy en un periodo de transición. [...]

La escritora del día se ha hecho más bien apóstol de la ciencia; se ha hecho periodista, da conferencias, aboga por la paz entre las naciones, trabaja y se esfuerza por ilustrar á los poderes públicos sobre la defensa de la salud y vida de los obreros é industriales.

Como podéis verlo, no hace literatura. Ha roto los moldes y los broqueles y traza las líneas de la idea con un cincel del espíritu práctico, más fecundo en bienes positivos (1902: 459-460).

Este cambio que describe Freyre de Jaimes - de la literatura a la escritura científica; de la cultura como forma de legitimación pero también práctica de ocio, a la profesionalización; de los versos leídos en la tertulia a la conferencia programática- se materializa en gran medida en un recambio generacional y en la emergencia de un nuevo modelo literario: la escritora intelectual. Este perfil autoral emergente, que acompaña el avance de la alfabetización femenina impulsada por el Estado desde finales del siglo XIX en el caso argentino, así como la creciente demanda laboral de una economía capitalista en expansión, promueve la impronta de una mujer de letras profesionalizada, enfocada ante todo en el mundo 
de la educación, cuya escritura funciona como una actividad que acompaña su profesión (en general, en términos secundarios) y que, en la mayoría de los casos, publica textos programáticos, ensayísticos o pedagógicos. ${ }^{4}$

Estas "nuevas escritoras" son las que llenan las páginas de Búcaro Americano y La Columna del Hogar, entre otros periódicos de la época. Carlota Garrido de la Peña, Elia M. Martínez y Ana Pintos (Amelia Palma) son las firmas que colaboran más asiduamente en estos semanarios porteños. Las tres se presentan, ante todo, como docentes y publican varios libros, pero ninguna de ellas participa activamente en ámbitos literarios como el Ateneo de Buenos Aires y, cuando intentan desarrollar una obra de ficción,se encuentran con múltiples obstáculos, como ha narrado en detalle Garrido de

4 Esta percepción de la escritora resulta, de hecho, sumamente perspicaz si se la contrasta con las decisiones que tomaron ella y sus compatriotas durante este período: tanto Freyre de Jaimes como Matto de Turner y Margarita Práxedes Muñoz (quien había publicado la novela programática La evolución de Paulina en 1893) abandonan la ficción cuando se instalan en Buenos Aires y se dedican a publicar libros ensayísticos y pedagógicos, así como periódicos más orientados a los debates intelectuales de la época - La Columna del Hogar (1902), La Revista Argentina (1902-1905) y Ameno y Útil (1910) en el primer caso; Búcaro Americano (1896- 1901 y 1906-1908), Boreales, Miniaturas y Porcelanas (1902), Viaje de recreo(1909) y Cuatro conferencias sobre la América del Sur (1909), en el segundo; y La filosofía positiva (1898) y Mis ensayos (1902), en el tercero. Asimismo, Aurora Cáceres recién publica su novela La rosa muerta (1914), así como otro libros, cuando ya está instalada en París, y la comitiva de la que forma parte Teresa González de Fanning cuando asiste al Congreso Femenino Internacional de 1910 está integrada casi exclusivamente por pedagogas, activistas de los derechos femeninos y mujeres dedicadas sobre todo a trabajos sociológicos, como Dora Mayer. 
la Peña en Mis recuerdos (1935). ${ }^{5}$ Es decir, escriben casi exclusivamente para el público femenino o infantil, sobre temas considerados "femeninos" y mensajes de tono moral. En este sentido, si por un lado el campo de las letras femeninas porteñas se expande gracias al crecimiento de la prensa y del público lector, por otro lado, se genderiza: comienza a restringirse a determinados modelos y discursos femeninos, así como tópicos y géneros literarios, como la literatura pedagógica y el melodrama sentimental, género literario que, como ha analizado Beatriz Sarlo (1985), eclosionó de la mano de los folletines seriados en el contexto argentino hacia los años 20.

Frente a este panorama y más allá de los obstáculos que encontraron en sus experiencias porteñas, las escritoras peruanas que se instalaron en Buenos Aires y lograron desarrollar una trayectoria como escritoras fueron las que se adaptaron a los cambios y reorientaron su perfil autoral a lo que percibían que podía tener éxito en la coyuntura del momento. Freyre de Jaimes, por ejemplo, postergó la idea de desarrollar una revista propia, a diferencia de lo que había hecho tanto en Perú como

5 Garrido de la Peña, quien también fundó La Revista Argentina (19021905) con Freyre de Jaimes, publicó más tarde algunas novelas y libros misceláneos, pero nunca dejó de ejercer la docencia y su mayor éxito fue el libro de lectura escolar Corazón argentino, reeditado varias veces tras su publicación inicial en 1913. Por otro lado, si bien jóvenes como María Torres Frías, María Emilia Passicot, Mercedes Pujato Crespo y la uruguaya Adela Castell también colaboraron asiduamente en estos semanarios y no se dedicaban en principio a la docencia, tampoco llegaron a desarrollar una carrera profesional y, en la mayoría de los casos, no lograron publicar un libro propio. Por lo tanto, se puede concluir que esta figura de escritora intelectual fue la más exitosa para las mujeres con ambiciones literarias de la época. 
en Bolivia con El Álbum, para asumir la dirección de una revista ajena: La Columna del Hogar. Esta publicación, al ser financiada por el diario El Nacional, estaba más orientada al consumo cultural femenino que a los debates literarios o al objetivo de promocionar la figura de su directora, aspectos que habían sido centrales en otros periódicos dirigidos por mujeres como La Alborada del Plata, en el caso de Gorriti, y Búcaro Americano, en el de Matto de Turner. Este puesto, además, se encontraba íntimamente relacionado con su cargo de secretaria en el Consejo Nacional de Mujeres, ya que el semanario funcionó como una plataforma para publicitar y fomentar las actividades de esta entidad al difundir sus actividades y los trabajos de sus principales integrantes, como Cecilia Grierson, Elvira López y Gabriela Laperrière de Coni, entre otras.

La Columna del Hogar desarrolló también varios de tópicos de época, como una abierta defensa de la profesionalización femenina (acotada a ciertas profesiones, como la docencia y los trabajos de oficina) que alternaba con la idealización del rol materno y un rígido discurso moral que advertía sobre los peligros del lujo y de la modernización. La publicación se centró, ante todo, en las múltiples actividades de las asociaciones femeninas de la época, además de incluir los clásicos artículos sobre moda, costumbres y crónicas sociales. Aunque se reprodujeron algunos relatos y poesías, la literatura ocupó claramente un lugar secundario, a diferencia de antecesoras como La Ondina del Plata, El Álbum del Hogar, y la propia Búcaro Americano, más centrada en la actividad intelectual del continente americano (aunque casi no incluyó en sus páginas relatos de ficción y difundió sobre todo poemas, a diferencia de sus predecesoras). Lo interesante en este punto es que, lejos de oponerse, el periódico de Matto de Turner y La Columna del Hogar mantuvieron un diálogo constante, a través de eventos y cola- 
boradoras compartidas (la propia escritora serrana publicó en el semanario en 1901 y 1902), de modo que compartieron un mismo circuito de lectura y sociabilidad.

Frente a este circuito periodístico constituido y a la expansión del público lector, Freyre de Jaimes intentaría algunos años después editar su propio periódico, La Revista Argentina. Para lograr este propósito, se asoció con una joven colega de Santa Fe: Carlota Garrido de la Peña. Si bien esta publicación tuvo menos circulación que el resto de las mencionadas, este gesto de asociación con una argentina más joven ofrece un dato de interés para analizar cómo lee Freyre de Jaimes el campo cultural de ese momento y cómo logra adaptarse a él. Con ello, muestra tener una mejor capacidad para habituarse que su compatriota Matto de Turner, escritora mucho más conocida y exitosa que ella, quien, sin embargo (y quizás justamente debido a su fama), insiste en un proyecto periodístico de tono más personal como Búcaro Americano, que no deja de traerle inconvenientes económicos y parece ser menos popular de lo que su directora esperaba. En este sentido, Matto de Turner logra adaptarse a su nueva situación y desarrollar una carrera que implica ciertos cambios en su figura de escritora, como alejarse de la literatura, dedicarse a su trabajo como docente y fortalecer la defensa del asociacionismo femenino y el americanismo en su revista, con lo 102 que dejaba en segundo plano, por ejemplo, la veta indigenista y de denuncia social que había desarrollado en su trilogía novelística). Sin embargo, quien parece percibir mejor por dónde pasa el incipiente mercado de bienes culturales y qué tipo de libros debe escribir una mujer para ser publicada en la Buenos Aires de fin de siglo es Carolina Freyre de Jaimes, al menos en lo que sostiene desde las páginas de La Columna del Hogar. En este punto, es notable cómo ella también opta 
por abandonar la literatura al poco tiempo de instalarse en la capital argentina. A pesar de que Búcaro Americano publica el capítulo de una novela social en preparación- "Dora" (1896) — , este proyecto es abandonado con el tiempo y su autora termina publicando Ameno y útil (1910), un libro de lecturas destinado al público escolarque la presenta como una escritora intelectual, más que como una novelista o poeta. ${ }^{6}$

Estas estrategias de adaptación de Freyre de Jaimes resultan en algún punto irónicas frente a la imagen conservadora que, en general, la crítica especializada ha ofrecido de la escritora, a excepción del reciente trabajo de Laura Liendo sobre sus crónicas en La Revista de Lima (2010). En ese sentido, casos como los de la escritora obligan a replantearse cómo hemos leído las obras de estas autoras, y hasta qué punto las prácticas y los discursos difieren -e incluso se contraponen- en las vidas de estas literatas. Como sus colegas con perfiles más abiertamente de avanzada (ya sea Matto de Turner o Cabello de Carbonera), Freyre de Jaimes busca de manera deliberada y activa desarrollar una carrera profesional en Buenos Aires, hacer circular sus textos e intervenir en ámbitos de discusión, al punto de revincularse con figuras de las cuales se había distanciado en la Lima de 1870, como Matto de Turner. Las distancias geográficas y temporales imponen otras políticas de amistad, otros géneros literarios a ensayar y otros mode-

6 En ese libro, además, Freyre de Jaimes desarrolla un perfil laudatorio de Juana Manuela Gorriti, con quien se había enemistado a finales de la década de 1870, tras la salida de la salteña del periódico que codirigían, El Álbum. Para un panorama más amplio sobre el conflicto entre ambas escritoras, me remito a la correspondencia de Gorriti editada por Graciela Batticuore (2004) y al trabajo de César Salas Guerrero sobre El Álbum (2010). 
los de escritora, y quien no se adapta permanece al margen del circuito. Esta quizás podría ser una manera de entender por qué una figura como la de Margarita Práxedes Muñoz ha quedado en un segundo plano a la hora de estudiar a las escritoras peruanas del siglo XIX, a pesar de estar conectada y aparecer en las páginas de Búcaro Americano y La Columna del Hogar. Diferente del modelo autoral que representan Cabello de Carbonera, Matto de Turner y Freyre de Jaimes quienes priorizan su perfil científico y positivista, Práxedes Muñoz no termina de ubicarse en el mapa que trazan las redes literarias y, paulatinamente, se ve "encapsulada", aislada de sus contemporáneas, en una historia literaria que, además, tiende a priorizar todavía los recortes nacionales y que deja al margen de sus focos de análisis este tipo de episodios e interlocuciones transnacionales. En ese sentido, creo que tanto el estudio de la prensa de la época como de la correspondencia de estas escritoras muestra una amplia gama de experiencias y claroscuros con los que las literatas se encontraron y frente a los cuales fueron desarrollando prácticas y estrategias autorales más o menos eficaces. Este amplio y complejo escenario nos ayuda a pensar en la figura de la escritora americana a finales del siglo XIX, sus mitos y realidades, así como los cambios con los que tuvo que lidiar a comienzos del siglo XX frente a los diversos procesos de modernización que atravesaron las naciones del continente en esos años.

Recibido: 10 de mayo del 2017

Aprobado: 18 de agosto del 2017 


\section{Bibliografía}

ALTAMIRANO, Carlos y Beatriz SARLO

1983 Ensayos argentinos. De Sarmiento a la vanguardia. Buenos Aires: Ariel.

ARIZA, Julia y Georgina GLUZMAN

2013 "Mujeres virtuosas e ilustradas: los retratos de Búcaro Americano. Periódico de las Familias (1896-1908)". En MALOSETTI COSTA, Laura y Marcela GENÉ (compiladoras). Atrapados por la imagen. Arte y politica en la cultura impresa argentina. Buenos Aires: Edhasa, pp. $75-107$.

AUZA, Néstor Tomás

1988 Periodismo y feminismo en la Argentina 1830-1930. Buenos Aires: Emecé.

BALTA, Aída

1998 Presencia de la mujer en el periodismo escrito peruano (18211960).Lima: San Martín de Porres.

BARRANCOS, Dora

2007 Mujeres en la sociedad argentina: Una historia de cinco siglos. Buenos Aires: Sudamericana.

2002 Inclusión/exclusión. Historia con mujeres. Buenos Aires: Fondo de Cultura Económica.

BATTICUORE, Graciela

2005 La mujer romántica. Lectoras, autoras y escritores en la Argentina: 1830-1870. Buenos Aires: Edhasa.

1999 El taller de la escritora. Veladas Literarias de Juana Manuela Gorriti, Lima-Buenos Aires (1876-7/1892). Rosario: Beatriz Viterbo.

2004 Cincuenta y tres cartas inéditas a Ricardo Palma: fragmentos de lo intimo: Buenos Aires-Lima, 1882-1891 (compiladora). Lima: Universidad San Martín de Porres. 
BELLUCCI, Mabel

1994 "De la pluma a la imprenta". En FLETCHER, Lea (compiladora.).Mujeres y cultura en la Argentina del siglo XIX. Buenos Aires: Feminaria, 1994, pp. 252-263.

CABELLO DE CARBONERA, Mercedes

1889 Blanca sol. Lima: Carlos Prince.

1948 La novela moderna. Estudio filosófico [1892]. Lima: El Cóndor.

CARLSON, Marifran

1988

¡Feminismo! The woman's movement in Argentina from its beginnings to Eva Perón. Chicago: Academy Chicago Publishers.

\section{CÁRDENAS MORENO, Mónica}

2012 La ética femenina en el Perú decimonónico: estudio de dos novelas de Mercedes Cabello de Carbonera: Blanca Sol y El Conspirador. Lima: Pontificia Universidad Católica del Perú. Tesis de maestría. Consulta: 20 de setiembre de 2017. http://tesis.pucp.edu.pe/repositorio/ handle/123456789/1208.

CORNEJO POLAR, Antonio

1992 ClorindaMatto de Tuner novelista. Estudios sobre Aves sin nido, Índole y Herencia. Lima: Lluviaeditores.

COT'T, Nancy F

1977 The Bonds of Womanhood: Woman's Sphere in New England, 1780-1835. New Haven: Yale UniversityPress, 1977.

DALMARONI, Miguel

2006 Una república de las letras: Lugones, Rojas, Payró: escritores argentinos y Estado. Rosario: Beatriz Viterbo Editora.

DEL ÁGUILA, Rocío

2011 Mujer, nación e identidad en la narrativa de Juana Manuela Gorriti y Clorinda Matto de Turner. Austin: Uni- 
versidad de Texas, 2011. Tesis doctoral. Consulta: 20 de setiembre de 2017. <https://repositories. lib.utexas.edu/bitstream/handle/2152/ETDUT-2011-12-4823/DEL-AGUILA-DISSERTATION.pdf?sequence $=1>$

DENEGRI, Francesca

1996 El abanico y la cigarrera. La primera generación de mujeres ilustradas en el Perú. Lima: Flora Tristán.

FERNÁNDEZ, Pura y Marie-Linda ORTEGA

2008 La mujer de letras o la letraberida. Textos y representaciones sobre la mujer escritora en el siglo XIX (editoras). MadridToulouse: Servicio de Publicaciones del CSIC.

FERNÁNDEZ, Pura

2015 No bay nación para este sexo: la $\operatorname{Re}(d)$ pública transatlántica de las Letras: escritoras españolas y latinoamericanas (18241936) (editora). Madrid: Iberoamericana.

FERNÁNDEZ BRAVO, Álvaro y Claudio MAÍZ

2009 Episodios en la formación de las redes culturales en América Latina (editores). Buenos Aires: Prometeo.

FERREIRA, Rocío

2009 "Cartografías pan/americanas en Cocina ecléctica (1890) de Juana Manuela Gorriti”. América sin nombre: boletín de la Unidad de Investigación de la Universidad de Alicante. Recuperaciones del mundo precolombino y colonial en el siglo XX bispanoamericano. Número 13, pp. 75-86.

FREYRE DE JAIMES, Carolina

1902 "Literatas y escritoras argentinas". La Columna del Hogar. Buenos Aires, año IV, número 177, pp. 459460.

1896 "Dora". Búcaro Americano. Buenos Aires, año I, número 2, pp. 28-30. 
Ameno y útil. Libro de lectura infantil. Buenos Aires: Ángel Estrada y Cía.

GARRIDO DE LA PEÑA, Carlota

1935 Mis recuerdos. Rosario: Imprenta "La Cervantina”.

HINTZE, Gloria

2005 "Clorinda Matto de Turner y el periódico Búcaro Americano: representación y redes latinoamericanas". EnGARCÍA BEDOYA, Carlos(compilador). Memorias JALLA. Lima: Universidad Nacional San Marcos, pp. 793-808.

LAERA, Alejandra

2014 Ficciones del dinero. Argentina, 1890-2001. Buenos Aires: Fondo de Cultura Económica.

LIENDO, Laura

2010 La construcción discursiva de la mujer limeña desde la perspectiva de Carolina Freyre de Jaimes en la "Revista de Lima" de 1872 a 1874. Tesis de grado. Lima: Universidad Nacional Mayor de San Marcos (mimeo).

LOBATO, Mirta Zaida

2007 Historia de las trabajadoras en la Argentina (1869-1960). Buenos Aires: Edhasa.

MATTO DE TURNER, Clorinda

Cuatro conferencias sobre América del Sur. Buenos Aires: Imprenta Juan B. Alsina. Aves sin nido. Valencia: F. Sempere y Compañía.

1896

1902

"Las obreras del pensamiento en la América del Sud". Búcaro Americano. Buenos Aires, año I, número 1, pp.5-14.

Boreales, miniaturas y porcelanas. Buenos Aires: Imprenta de Juan A. Alsina. 
MISERES, Vanesa

2010 Trazos de nación: mujeres viajeras y discurso nacional en Latinoamérica (1830-1910). Nashville: Universidad de Vanderbilt. Tesis de doctorado. Consulta: 20 de setiembre de 2017. http://etd.library.vanderbilt.edu/ available/etd-10192010-115639/unrestricted/miseres.pdf.

NARI, Marcela

$2000 \quad$ "El feminismo frente a la cuestión de la mujeren las primeras décadas del siglo XX”. En SUR I A NO, Juan (compilador)La cuestión social en Argentina, 18701943. Buenos Aires: La Colmena, pp. 277-300.

2004 Politicas de maternidad y maternalismo politico: Buenos Aires, 1890-1940. Buenos Aires: Biblos.

PELUFFO, Ana

2015 "That damned mob of scribbling women": gendered networks in fin de siècle Latin America (1898-1920)". En RODRÍGUEZ, Ileana y Mónica SZURMUK (editoras).The Cambridge History of Latin American Women's Literature. Cambridge: Cambridge University Press, pp. 149-163.

2005a "Desencuentros de la sororidad republicana en el Perú de fin de siglo". EnANDRÉ, María Claudia y Patricia RUBIO (compiladoras). Entre mujeres: Colaboraciones, influencias e intertextualidades en la literatura y el arte latinoamericanos. Santiago de Chile: RIL, pp. 141.

2005b Lágrimas andinas: sentimentalismo, género y virtud republicana en Clorinda Matto de Turner. Pittsburg: Universidad de Pittsburg.

PINTO VARGAS, Ismael

2003 Sin Perdón y Sin Olvido Mercedes Cabello de Carbonera y su mundo. Lima: Universidad San Martín de Porres. 
SALAS GUERRERO, César

2010 "El Álbum, una revista limeña para el bello sexo (1874-1875)". En PINTO VARGAS, Ismael (editor).Primer simposium internacional Mercedes Cabello de Carbonera y su tiempo (1909-2009). Lima: San Martín de Porres,pp. 135-153.

SARLO, Beatriz

1985 El imperio de los sentimientos. Narraciones de circulación periódica en la Argentina (1917-1927). Buenos Aires: Catálogos.

SOTOMAYOR, Evelyn

2014 Satisfecha y orgullosa, aunque sea impropio. Las veladas literarias de Clorinda Matto de Turner (1887-1891?). Lima: Pontificia Universidad Católica del Perú. Tesis de maestría. Consulta: 20 de septiembre de 2017. <http://tesis.pucp.edu.pe/repositorio/handle/123456789/5254>

TAUZIN CASTELLANOS, Isabelle

1995 "La narrativa femenina en el Perú antes de la guerra del Pacífico". Revista de crítica literaria latinoamericana. Año 21, número 42, pp. 161-187.

1989 Le roman feminin peruvien pendant la seconde moitie du XIX siècle. Thèse de Doctorat présentée et soutenue publiquement. Université de Poitiers. Faculté des Lettres et des Langues. <https://doi.org/10.2307/4530830>

110 VARGAS YÁBAR, Miguel

2013 Las empresas del pensamiento. Clorinda Matto de Turner (1852-1909). Lima: Grupo Pakarina.

VICENS, María

2015

"Lectoras de patria grande: escritoras sudamericanas en la prensa porteña finisecular". Revista de Crítica Literaria Latinoamericana. Tufts University, número 82, pp. 193-219. 
ZANETTI, Susana

1994 "Búcaro Americano: Clorinda Matto de Turner en la escena femenina porteña". En FLETCHER, Lea (compiladora). Mujeres y cultura en la Argentina del siglo XIX. Buenos Aires: Feminaria, pp. 264-275.

ZIMMERMAN, Eduardo

1995 Los liberales reformistas: La cuestión social en la Argentina, 1890-1916. Buenos Aires: Editorial SudamericanaUniversidad de San Andrés. 